\title{
Prevalence of metabolic syndrome and its components in patients presenting to tertiary care center
}

\author{
Ramesh Raj Acharya', Dipak Kunwar'2, Susmita Khadka³, Rajyashree Kunwar4, \\ Adhyashree Karki ${ }^{5}$, Rakshya Shrestha ${ }^{6}$ \\ ${ }^{1}$ Lecturer, Department of Medicine, Manipal College of Medical Sciences, Pokhara, Nepal, ${ }^{2}$ Assistant Professor, \\ Department of Psychiatry, Kathmandu University School of Medical Sciences (KUSMS), Dhulikhel, Kavre, Nepal, \\ ${ }^{3}$ Resident, Department of Psychiatry, Interfaith Medical Center, Brooklyn, New York, USA, ${ }^{4}$ Senior Program Manager, \\ National Center for AIDS and STD Control, Save The Children, Nepal, ${ }^{5}$ Resident -DM, Department of Gastroenterology, \\ College of Medical Sciences, Bharatpur, Nepal, ${ }^{6}$ Assistant Professor, Institute of Medicine, Maharajgunj, Kathmandu, Nepal
}

\section{A B STR A C T}

Background: The prevalence of metabolic syndrome ranges from 10 to $84 \%$, depending upon sex, age, race, ethnicity, region and the definition used globally. There is limited literature in the prevalence of metabolic syndrome in Nepal. A nationwide survey study reported prevalence of metabolic syndrome to be $15 \%$ and $16 \%$ according to ATP III and IDF criteria respectively. Aims and Objectives: The aims and objective of our study is to study the prevalence of metabolic syndrome and its components in tertiary care center. Materials and Methods: This was a descriptive cross-sectional study. We used convenient method of sampling and data collection was done in between May 2019 to July 2019. Bivariate and multivariate logistic regression analysis was done for association of metabolic syndrome with different variables. Results: A total of 362 participants were included in the study. Among them $54.4 \%$ were $\geq 53$ years and $45.6 \%$ were $<53$ years of age. Among all the participants, $25 \%$ were diabetic and $55 \%$ were hypertensive. Metabolic syndrome was found in $45.3 \%$. All components of metabolic syndrome were found to be significantly associated with metabolic syndrome both in bivariate and multiple regression analysis. Conclusion: The metabolic syndrome is very prevalent in our population. These findings prompt the concerned authorities to formulate strategies to prevent the risk factors.

Key words: Metabolic syndrome; Prevalence; Nepal
Access this article online

Website:

http://nepjol.info/index.php/AJMS

DOI: 10.3126/ajms.v11i4.29037

E-ISSN: 2091-0576

P-ISSN: $2467-9100$

Copyright (c) 2020 Asian Journal of Medical Sciences

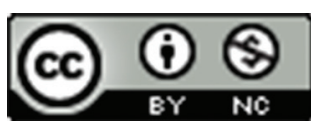

This work is licensed under a Creative Commons Attribution-NonCommercial 4.0 International License.

\section{INTRODUCTION}

The concept of metabolic syndrome (MetS) is in literature since long time. The concept was developed way back in 1920 when Kylin, a Swedish physician found an association between hyperglycemia, high blood pressure and gout. The World Health Organization (WHO) first developed its definition in 1998 because insulin resistance was felt to be central to the pathophysiology of metabolic syndrome, evidence for insulin resistance is an absolute requirement in the WHO definition. ${ }^{1}$ Since then different definition and modification has been proposed from different organization. National Cholesterol Education Program
(NCEP) Adult Treatment Panel III (ATP III) defines metabolic if three or more of the following five criteria are met: waist circumference over 40 inches (men) or 35 inches (women), blood pressure over 130/85 $\mathrm{mmHg}$, fasting triglyceride (TG) level over $150 \mathrm{mg} / \mathrm{dl}$, fasting high-density lipoprotein (HDL) cholesterol level less than $40 \mathrm{mg} / \mathrm{dl}$ (men) or $50 \mathrm{mg} / \mathrm{dl}$ (women) and fasting blood sugar over $100 \mathrm{mg} / \mathrm{dl}^{2}$

Recently, international diabetes federation (IDF), National Heart, Lung and Blood Institute (NHLBI), American Heart Association (AHA), World Heart Federation (WHF), International Atherosclerosis Society (IAS) and 
International Association for the Study of Obesity (IASO) have proposed a new harmonized definition which requires any three of the five components included in the IDF definition for the diagnosis of MetS and do not consider central obesity as an obligatory component. ${ }^{3}$

Globally prevalence of metabolic syndrome ranges from 10 to $84 \%$, depending upon sex, age, race, and ethnicity, region and the definition used. ${ }^{4}$

There is limited literature in the prevalence of metabolic syndrome in Nepal. One nationwide survey study reported prevalence of metabolic syndrome is $15 \%$ and $16 \%$ according to ATP III and IDF criteria respectively.

\section{Aims and objectives}

The aims and objectives of our study is to study the prevalence of metabolic syndrome and its components in tertiary care center.

\section{MATERIALS AND METHODS}

\section{Ethical approval}

The study was initiated after receiving approval from the Institutional Review Committee (IRC), Kathmandu medical college. Informed consent was obtained from all studied participants.

\section{Study design and setting}

This was a Descriptive cross-sectional study. All the patients presenting to medicine OPD for regular check-up who were ready to participate were included in the study. We used convenient method of sampling and data collection was done in between May 2019 to July 2019. Informed consent was obtained once participants were agreed for the study. The study was conducted in Kathmandu Medical College, Kathmandu, Nepal

\section{Instruments}

\section{Proforma}

We designed a questionnaire focusing on sociodemographic profile of patients. The questions concerned: age, sex, occupation, education, personal history of medical illness.

\section{Metabolic syndrome criteria}

1. Waist measurement (Males $\geq 90 \mathrm{~cm}$ and females $\geq 80 \mathrm{~cm}$ )

2. Raised triglycerides: $\geq 150 \mathrm{mg} / \mathrm{dL}$

3. Reduced HDL cholesterol: $<40 \mathrm{mg} / \mathrm{dL}$ in men and $<50 \mathrm{mg} / \mathrm{dL}$ in women;

4. Raised blood pressure: $\geq 130 / 85 \mathrm{~mm} \mathrm{Hg}$.

5. Raised plasma fasting glucose: $\geq 100 \mathrm{mg} / \mathrm{dL}$.

\section{Statistics}

Chi square test address relationship of different variables. The Statistical Package for Social Science software (IBM SPSS Statistics 21, Chicago, USA) was used for analysis.

\section{RESULTS}

The total of 362 participants was included in the study. Among them $54.4 \%$ were 53 years of age and above and $45.6 \%$ were below 53 years of age. We had equal number of male and female participants. The more than half (57.7\%) had formal education and $42.3 \%$ had no formal education. Around half of them (51.4\%) were not working so not having regular income. Among all participants $25 \%$ were diabetic and 55\% were hypertensive Other recorded variables are depicted in Table 1.

Among all participants metabolic syndrome was found in $45.3 \%$ (Table 2). All components of metabolic syndrome found to be highly significantly associated with metabolic syndrome both in bivariate and multiple regression analysis (Table 3).

\begin{tabular}{|c|c|c|c|}
\hline Variables & & $\mathrm{N}=362(\%)$ & $\begin{array}{c}\text { Statistics } \\
x^{2} \\
\text { df } \\
\text { p-value }\end{array}$ \\
\hline \multirow[t]{2}{*}{ Age } & $<53$ years & $165(45.6)$ & 6.20 \\
\hline & $\begin{array}{l}53 \text { years and } \\
\text { Above }\end{array}$ & $197(54.4)$ & $\begin{array}{c}1 \\
0.01\end{array}$ \\
\hline \multirow[t]{2}{*}{ Sex } & Male & $181(50)$ & 2.18 \\
\hline & Female & $181(50)$ & $\begin{array}{c}1 \\
0.13\end{array}$ \\
\hline \multirow[t]{2}{*}{ Education } & No formal & $153(42.3)$ & 0.62 \\
\hline & Formal & $209(57.7)$ & $\begin{array}{c}1 \\
0.43\end{array}$ \\
\hline \multirow{2}{*}{ Working status } & Earning & $176(48.6)$ & 1.23 \\
\hline & Not earning & $186(51.4)$ & $\begin{array}{c}1 \\
0.26\end{array}$ \\
\hline \multirow[t]{3}{*}{ Alcohol use } & Yes & $51(14)$ & 2.05 \\
\hline & No & $295(81.5)$ & 3 \\
\hline & Ex-user & $15(4.5)$ & 0.56 \\
\hline \multirow[t]{3}{*}{ Tobacco use } & Yes & 32 (8.8) & 0.43 \\
\hline & No & $321(88.7)$ & 2 \\
\hline & Ex-user & $9(2.7)$ & 0.80 \\
\hline \multirow[t]{2}{*}{ HTN } & Yes & $199(55)$ & 58.87 \\
\hline & No & $163(45)$ & $\begin{array}{c}1 \\
0.000\end{array}$ \\
\hline \multirow[t]{2}{*}{ DM } & Yes & $90(25)$ & 24.41 \\
\hline & No & $272(75)$ & $\begin{array}{c}1 \\
0.000\end{array}$ \\
\hline \multirow[t]{3}{*}{ BMI } & $<25$ & $160(44.2)$ & 17.16 \\
\hline & 25 and above & $202(55.8)$ & 1 \\
\hline & & & 0.000 \\
\hline
\end{tabular}

Asian Journal of Medical Sciences | Jul-Aug 2020 | Vol 11 | Issue 4 


\section{DISCUSSION}

In our study, the overall prevalence of metabolic syndrome was $45.4 \%$.

Prevalence from our study is much higher when compared to the first national representative estimates on prevalence survey which included 4200 adults aged 15-69 years from 210 clusters selected proportionately across Nepal's three ecological zones (Mountain, Hill and Terai) which reported 15\% prevalence using ATP III criteria. ${ }^{5}$

Depending on the study participants and criteria used, Metabolic syndrome has been documented in 15\% to $57.4 \%$ cases of Nepal. ${ }^{6}$

The higher prevalence in the present study may be explained by the study population, our participants were taken from the medicine OPD so they could not be compared to general healthy population. Beside that our study represents more recent data (obtained in 2019) compared with the previous study which was conducted in 2010, over which time the prevalence may have truly increased.

\begin{tabular}{|c|c|c|c|}
\hline Variables & & $\mathrm{N}=362(\%)$ & $\begin{array}{c}\text { Statistics } \\
x^{2} \\
\text { df } \\
\text { p-value }\end{array}$ \\
\hline Triglyceride & $\begin{array}{l}<150 \\
150 \text { and above }\end{array}$ & $\begin{array}{l}167(46) \\
195(54)\end{array}$ & $\begin{array}{c}85.50 \\
1 \\
0.000\end{array}$ \\
\hline HDLc & $\begin{array}{l}>40 \mathrm{M} \text { and }>50 \\
\mathrm{~F} \\
<40 \mathrm{M} \text { and }<50 \\
\mathrm{~F}\end{array}$ & $\begin{array}{l}135(37.3) \\
227(62.7)\end{array}$ & $\begin{array}{c}30.17 \\
1 \\
0.000\end{array}$ \\
\hline FBS & $\begin{array}{l}<100 \\
100 \text { and above }\end{array}$ & $\begin{array}{l}218(60) \\
144(40)\end{array}$ & $\begin{array}{c}85.09 \\
1 \\
0.000\end{array}$ \\
\hline $\mathrm{BP}$ & $\begin{array}{l}<130 \text { systolic or } \\
<85 \text { diastolic } \\
=\text { or }>130 \\
\text { systolic or }=>85 \\
\text { diastolic }\end{array}$ & $\begin{array}{l}199(55) \\
163(45)\end{array}$ & $\begin{array}{c}58.87 \\
1 \\
0.000\end{array}$ \\
\hline Waist & $\begin{array}{l}\text { No obesity } \\
\text { obesity }\end{array}$ & $\begin{array}{l}221(61) \\
141(39)\end{array}$ & $\begin{array}{c}57.83 \\
1 \\
\mathbf{0 . 0 0 0}\end{array}$ \\
\hline
\end{tabular}

Our results show national burden of non-communicable disease in Nepal is increasing. The Nepal Burden of Disease 2017 study shows that NCDs are the leading causes of death with two thirds $(66 \%)$ of death attributed to NCDs. Of the total deaths in the country, ischemic heart disease contributes to nearly one in six deaths $(16 \%){ }^{7}$

A recent population-based prevalence study of selected NCDs in Nepal shows $12 \%$ prevalence of diabetes $8.5 \%$ and 3\% coronary artery diseases among population aged 20 years and above. The outpatient data reported in annual report of Department of Health Services (DoHS) also shows increasing trend of NCD cases in later years in Nepal. ${ }^{8}$

Prevention of the development of the first metabolic syndrome component may have significant public health benefits as the presence of one component is predictive of the development of metabolic syndrome. Therefore, the study of individual components of metabolic syndrome is also very important. The highest prevalence among metabolic syndrome in our study was low HDL cholesterol $(62.7 \%)$, followed by triglyceride (54\%), and hypertension (45\%).Nationwide populations study reported triad of low HDL-C, abdominal obesity and high BP was the most prevalent $(8.18 \%)$, followed by abdominal obesity, low HDL-C cholesterol and high triglycerides $(8 \%){ }^{5}$

Among socio demographic factor the age was significantly associated with metabolic syndrome. Our finding was in accordance with study from Khan Y et al. ${ }^{9}$

In neighboring countries such as in India hyperglycemia was the most common $(29.2 \%),{ }^{9}$ and in China, the most prevalent component was hypertension $(24.52 \%)$, followed by dyslipidaemia $(24 \%)^{10}$ and central obesity $(22.07 \%){ }^{10}$ European country such as Poland, displayed a different pattern starting from top to bottom, abdominal obesity $(75.1 \%)$, hypertension $(71 \%)$ and insulin resistance $(37.3 \%)^{11}$

Each study and country held a different pattern for the prevalence of each metabolic syndrome component, this finding might be due to wide variations of cultural background, demographic and socioeconomic factors.

\begin{tabular}{|c|c|c|c|c|c|c|c|}
\hline \multirow[t]{2}{*}{ Variables } & \multicolumn{2}{|c|}{ Unstandardized coefficients } & \multirow{2}{*}{$\begin{array}{c}\text { Standardized coefficients } \\
\text { Beta }\end{array}$} & \multirow[t]{2}{*}{$t$} & \multirow[t]{2}{*}{$\mathbf{P}$} & \multicolumn{2}{|c|}{$95 \% \mathrm{Cl}$} \\
\hline & B & SE & & & & lower & Upper \\
\hline Triglyceride & 0.35 & 0.02 & 0.35 & 12.4 & 0.000 & 0.30 & 0.41 \\
\hline HDLC & 0.31 & 0.02 & 0.30 & 10.7 & 0.000 & 0.25 & 0.37 \\
\hline FBS & 0.40 & 0.03 & 0.39 & 13.4 & 0.000 & 0.34 & 0.46 \\
\hline $\mathrm{BP}$ & 0.36 & 0.02 & 0.36 & 12.86 & 0.000 & 0.31 & 0.42 \\
\hline Waist & 0.29 & 0.03 & 0.28 & 9.75 & 0.000 & 0.23 & 0.35 \\
\hline
\end{tabular}


However, low HDLc cholesterol among the most highly prevalent metabolic component among young generation is widely accepted and consistent finding. ${ }^{12}$

The most highlighting finding from our study was that all components of metabolic syndrome were found to be significantly associated with metabolic syndrome both in bivariate as shown in Table 2 and multivariate analysis as shown in Table 3. Epidemiological studies have shown that the risk of multiple risk factors was much more than the sum of accompanying single risk factors, ${ }^{13,14}$ and whether the risk of MetS was greater than the sum of its individual components has been debated..$^{15}$ But we did not further explore the relationship between different trait combinations and risk for metabolic syndrome.

Our study has several limitations that should be considered. Firstly, data were collected from OPD so they may not be generalizable. Second, factors like sedentary life style and diet habit were not considered in our study. Another important factor was the genetic factor. The South Asian population have been shown to be genetically susceptible to central obesity and insulin resistance. We have no genetic studies available in Nepalese population so the role of genetic factors in the pathogenesis of metabolic syndrome could not be assessed. As it is a single centre study, it cannot cover the whole nation and results may vary from other parts of the nation.

\section{CONCLUSION}

The metabolic syndrome is very prevalent in our population and the most highly prevalent component among metabolic syndrome is low HDLc cholesterol level. Those with increasing age are at particular risk. These findings prompt the concerned authorities of Nepal to formulate strategies to prevent the risk factors.

\section{REFERENCES}

1. Alberti KG and Zimmet P. Definition, diagnosis and classification of diabetes mellitus and its complications. Part 1: diagnosis and classification of diabetes mellitus provisional report of a WHO consultation. Diabet Med 998; 15:539-553.

https://doi.org/10.1002/(SICI)1096-9136(199807)15:7<539:: AID-DIA668>3.0.CO;2-S

2. Grundy SM, Cleeman JL, Daniels SR, Donato KA, Eckel RH, Franklin BA, et al. Diagnosis and management of the metabolic syndrome: an American Heart Association/National Heart, Lung and Blood Institute scientific statement. Circulation 2005;112, 2735- 2752.
https://doi.org/10.1161/CIRCULATIONAHA.105.169404

3. Alberti KG, Eckel RH, Grundy SM, Zimmet PZ, Cleeman JI, Donato KA. Harmonizing the metabolic syndrome. A joint interim statement of the international diabetes federation task force on epidemiology and prevention; national heart, lung, and blood institute; American heart association; World heart federation; International atherosclerosis society; and International association for the study of obesity. Circulation 2009;120: 1640-1645. https://doi.org/10.1161/CIRCULATIONAHA.109.192644

4. Khan Y, Lalchandani A, Gupta AC, Khadanga S and Kumar S. Prevalence of metabolic syndrome crossing $40 \%$ in Northern India: Time to act fast before it runs out of proportions. J Family Med Prim Care 2018;7(1):118-123.

https://doi.org/10.4103/jfmpc.jfmpc_10_17

5. Mehata S, Shrestha N, Mehta RK, Bista B, Pandey AR and Mishra SR. Prevalence of the Metabolic Syndrome and its determinants among Nepalese adults: Findings from a nationally representative cross-sectional study. Sci Rep.2018; 8: 14995. https://doi.org/10.1038/s41598-018-33177-5

6. Rajbhandari A, Pandeya D, Bhattarai M, Malla R, Sharma A, Shrestha D, et al. Prevalence of Metabolic Syndrome and its Component in Patients with Acute Coronary Syndrome. Medical Journal of Shree Birendra Hospital 2015; 12(2), 42-48. https://doi.org/10.3126/mjsbh.v12i2.12928

7. http://nhrc.gov.np/wp-content/uploads/2019/07/NCDs-policy-brief.pdf

8. NHRC (2019). Population Based Prevalence of Selected NonCommunicable Diseases in Nepal. Kathmandu: Nepal Health Research Council, Government of Nepal.

9. Khan $Y$, Lalchandani A, Gupta AC, Khadanga S and Kumar S. Prevalence of metabolic syndrome crossing $40 \%$ in Northern India: Time to act fast before it runs out of proportions. J Family Med Prim Care 2018; 7: 118-123.

https://doi.org/10.4103/jfmpc.jfmpc_10_17

10. Herningtyas $\mathrm{EH}$ and $\mathrm{Ng} \mathrm{TS}$. Prevalence and distribution of metabolic syndrome and its components among provinces and ethnic groups in Indonesia. BMC Public Health 2019; 19(1):377. https://doi.org/10.1186/s12889-019-6711-7

11. Janszky I, Vatten L, Romundstad P, Laugsand LE, Bjorngard JH, Manczuk M, et al. Metabolic syndrome in Poland - the PONS study. Ann Agric Environ Med 2011; 18(2):270-272.

12. Nolan PB, Carrick-Ranson G, Stinear JW, Reading SA and Dalleck LC. Prevalence of metabolic syndrome and metabolic syndrome components in young adults: A pooled analysis. Prev Med Rep 2017; 7: 211-215. https://doi.org/10.1016/j.pmedr.2017.07.004

13. Li W, Wang D, Wang X, Gong Y, Cao S, Yin X, et al. The association of metabolic syndrome components and diabetes mellitus: evidence from China National Stroke Screening and Prevention Project. BMC Public Health 2019; 19: 192. https://doi.org/10.1186/s12889-019-6415-z

14. Kahn R, Buse J, Ferrannini E and Stern M. The metabolic syndrome: time for a critical appraisal: joint statement from the American Diabetes Association and the European Association for the Study of diabetes. Diabetes Care 2005;28(9):2289- 2304. https://doi.org/10.2337/diacare.28.9.2289

15. Grundy SM. Metabolic syndrome: connecting and reconciling cardiovascular and diabetes worlds. J Am Coll Cardiol 2006;47(6):1093-1100.

https://doi.org/10.1016/j.jacc.2005.11.046 
Authors Contribution:

RRA-Concept and design of the study, review the literature manuscript preparation and critical revision of the manuscript; DK-Statistically analyzed data and interpreted and prepared first draft of manuscript; SK-literature search and helped in preparing first draft of manuscript; RK-Collected data and literature search; AK-Collected data, literature search; RS-Concept of study, manuscript preparation and review of study.

\section{Work attributed to:}

Department of Medicine, Kathmandu Medical College, Kathmandu, Nepal.

\section{Orcid ID:}

Dr. Ramesh Raj Acharya- (D) https://orcid.org/0000-0002-1373-5642

Dr. Dipak Kunwar- (1) https://orcid.org/0000-0001-8480-5217

Dr. Susmita Khadka- https://orcid.org/0000-0003-1795-5439

Dr. Rajyashree Kunwar- (i) https://orcid.org/0000-0001-5615-8788

Dr. Adhyashree Karki- https://orcid.org/0000-0002-1090-5116

Dr. Rakshya Shrestha- https://orcid.org/0000-0002-5857-2330

Source of support: None, Conflicts of Interest: None 